\title{
Serebral palside erken tanı
}

\author{
Early diagnosis in cerebral palsy
}

\author{
Müge Ayanoğlu, Ayşe Tosun
}

Aydın Adnan Menderes Üniversitesi Tıp Fakültesi, Çocuk Nörolojisi Bilim Dalı, Aydın

\begin{abstract}
Serebral palsi, kalıcı motor fonksiyon bozukluğunun çocuklardaki en sık nedenidir. Serebral palsi tanısı alan olgulara erken dönemde tedavi başlanmasının, nörolojik sonuçları iyileştirdiği bilinmektedir. Bu nedenle riskli bebeklerin tanınması ve yakın klinik izlemi büyük önem taşır. Serebal palsinin erken dönemde tanınmasında yol gösterici bulgular; i) ilkel reflekslerin normal seyri göstermemesi, ii) nörolojik gelişim basamaklarında gerilik, iii) genel hareketlerin akıcı özelliğini kaybedip rijit bir hal alması, iv) genel hareketlerin fidgety (kıpır kıpır) özelliğini yitirmesi, v) düşük Hammersmith infant nörolojik değerlendirme (HINE) skorları ve vi) neonatal dönemde evre III ve IV intrakranial kanama, kistik periventriküler lökomalazi (PVL), bazal ganglion hasarı, diffüzyon kısıtlılığı gibi görüntüleme bulgularının varlığı olarak özetlenebilir.
\end{abstract}

Anahtar sözcükler: serebral palsi; tanı; erken tanı
Cerebral palsy is one of the most common causes of permanent physical and developmental disability in children. Early physical therapy and rehabilitation programs improve long-term neurological outcomes. Thus, early detection of high-risked infants and clinical follow-up is essential. The important findings for the early diagnosis in children with cerebral palsy are; i) abnormal course of primitive reflexes, ii) delayed motor milestones, iii) the lack of normal smooth and fluent character of general movements, iv) the absence of general movements of fidgety character, v) low Hammersmith infant neurological examination (HINE) scores, and vi) abnormal neuroradiological findings in the neonatal period as grade III and IV intracranial hemorrhage, cystic periventricular leukomalacia, injury of basal ganglia, and diffusion restriction.

Key words: cerebral palsy; diagnosis; early diagnosis erebral palsi (SP), çocukluk çağında en sık görülen fiziksel engellilik nedenidir ve 1000 canlı doğumda 2-3 sıklığında görülmektedir. Sıklıkla motor semptomların oluşturduğu ilerleyici olmayan, klinik olarak tanımlanabilen, değişken derecelerde fiziksel ve gelişimsel bozukluklara neden olabilen bir tablodur. ${ }^{[1]}$ William John Little 1861 yılında, prematüre doğan ya da zor doğum eylemi yaşayan bebeklerde ekstremitelerde tetanus benzeri rijiditeyi ve distorsiyonu tanımlamıştır. ${ }^{[2]}$ On dokuzuncu yüzyılın sonlarında aynı zamanda Little Hastalığı olarak anılan SP'nin tanımı, Rosenbaum ve ark. tarafindan 2006 yılında yayımlanan bir rapora göre; gelişmekte olan fetal ya da infantil beyinde, ilerleyici olmayan hasara bağlı, fiziksel aktiviteyi sınırlandıran, hareket ve postür bozukluğu olarak güncellenmiştir. SP'de motor bozukluğa, görme, işitme, algı, kognisyon (biliş), davranış, iletişim alanlarında problemler ve epilepsi eşlik edebilir. ${ }^{[3]}$ SP'nin; i) spastik, ii) diskinetik (distonik ya da atetoik), iii) ataksik ve iv) hipotonik olmak üzere toplam dört tipi vardır. Mikst tipleri de görülebilir. En sık görülen spastik tip SP, tutulan ekstremite bölgelerine göre hemiplejik, diplejik ve kuadriplejik olmak üzere alt tiplere ayrılır. Diğer tiplerinin tamamında ise dört ekstremite birden etkilenmiştir. ${ }^{[4]}$ SP tanısı, doğum öncesi, doğum ve sonrasına ait risk etmenleri olan çocuklarda, gelişim basamaklarına geç ulaşma, ilerleyici olmayan motor gerilik, postür bozukluğu, istemsiz hareketler, tonus artışı ve artmış derin tendon reflekslerinin varlığı ile kolaylıkla koyulur. Ancak tipik bulgular 12-24 ay civarında görülmeye başladığından, SP tanı ve tedavisi gecikebilir. ${ }^{[5]}$ Beynin hızla büyüdüğü, yapısal ve fizyolojik değişikliğe uğrama yeteneği olarak bilinen nöronal plastisitenin en aktif olduğu

- İletişim adresi: Dr. Müge Ayanoğlu, Aydın Adnan Menderes Üniversitesi Tıp Fakültesi, Çocuk Nörolojisi Bilim Dalı, 09010, Kepez Mevkii, Efeler, Aydın,Türkiye Tel:0256-2182000 e-posta: mugeayanoglu_05@hotmail.com

- Geliș tarihi: 21 Șubat $2021 \quad$ Kabul tarihi: 6 Mart 2021 
dönemde fiziksel, sosyal, görsel ve işitsel alanlarda rehabilitasyonun başlanması özürlülüklerin azaltılmasında önemli rol oynayacağı ve uzun dönem nörolojik sonuçlara olumlu katkılar sağlayacağı için, SP'nin erken tanısı son derece önemlidir. ${ }^{[6]}$ Erken tanı ve rehabilitasyon, hem SP'li olguların hem de ailelerinin yaşam kalitelerini artırmayı hedefler. Bu yazıda serebral palside erken tanı konusu kaleme alınmıştır.

\section{SEREBRAL PALSI TANISI}

SP tanısı, ayrıntılı öykü ile klinik risk faktörlerinin incelenmesine, gelişim basamaklarının değerlendirilmesine, rutin nörolojik muayenenin yanı sıra ilkel reflekslerin, genel hareketlerin değerlendirilmesine ve merkezi sinir sisteminin görüntüleme bulgularına dayanır. ${ }^{[5]}$

\section{Risk Faktörleri}

Öyküde risk faktörlerini iyi sorgulamak, riskli bebeklerin tanınmasına katkı sağlayacağı için büyük önem taşır. Prenatal dönemde annenin kronik hastalıkları (nörolojik, hematolojik, metabolik, endokrin, kardiyak ve renal hastalıkları), obezitesi, alkol/ilaç ya da sigara kullanımı, anne yaşının 20'den küçük ya da 34'ten büyük olması, maternal enfeksiyonların varlığı, çoğul gebelik, çok sayıda gebelik öyküsü, gebelikler arası sürenin kısa olması, daha önce düşük/ intrauterin fetal ölüm ya da SP'li çocuk sahibi olma öyküsü ve travma, SP'nin prenatal risk faktörleri olarak kabul edilir. ${ }^{[7]}$

Prematürelik ise SP için önemli bir perinatal risk faktörüdür. Normal bir gebelik 38-40. gestasyonel haftalar arasında sonlanır. Otuz yedinci gestasyonel haftadan daha önce sonlanan gebeliklerde ise prematürelikten söz edilir. Hirvonen ve ark.'nın 1.018.302 infantta yapmış oldukları geniş bir epidemiyolojik çalışmada; tüm olguların \%0,2'si SP tanısı almıştır. SP insidansı 32 hafta altında doğanlarda \%8,7, 32-34 hafta arasında doğanlarda \%2,4, 34-36 hafta arasında doğanlarda $\% 0,6$ ve zamanında doğanlarda $\% 0,1$ olarak saptanmıştır. Aynı çalışmada 32 hafta altında ve 32-34 hafta arasında doğan bebeklerde resusitasyon ihtiyacının olması, ilk yatışta antibiyotik gereksiniminin olması, 5. dk APGAR (Appearance, Pulse, Grimace, Activity and Respiration) skorunun $<7$ olması ve intrakranial kanama varlığında SP olma olasılığının arttığı tespit edilmiştir. ${ }^{[7]}$ Görüntüleme bulgularında, periventriküler lökomalazi (PVL) ve intrakranial hemoraji varlığı preterm infantların SP olma olasılığını artıran önemli risk faktörleridir. Yardımcı üreme tekniklerinin kullanılmış olması, çoğul gebeliğe ikincil düşük doğum ağırlığı ve prematürelik olasılığını artırdığı için SP için birer risk faktörüdür. Çoğul gebeliklerde, fetüslerden birinin intrauterin ölmesi halinde, diğer fetüste SP gelişme olasılığının \%20 olduğu belirtilmektedir. ${ }^{[8]}$ Fetüsün yavaş büyümesine ve anormal beyin gelişimine neden olan intrauterin gelişim geriliğinin, term bebeklerde SP riskini 10-30 kat artırdığına dair yayınlar mevcuttur. ${ }^{[9]}$ Perinatal dönemde öyküde; uzamış doğum eylemi, fetal kalp hızındaki değişmeler, amnion sıvısının mekonyumlu olup aspire edilmesi, aspirasyon pnömonisi, solunum sıkıntısı, hipoksi, pulmoner hipertansiyon ve ağır kardiyo-pulmoner yetmezlik tablolarına yol açarak hipoksik hasara neden olabilir. ${ }^{[10]}$ Doğum sonu 5.-10. dakika APGAR skorunun 5'in altında olması, canlandırma gereksiniminin olması, kordon kanı kan gazında $\mathrm{CO}_{2}$ artışı ve düşük $\mathrm{pH}$ asfiksiyi destekleyen objektif verilerdir. Hipoksik doğum sonrası hipoksik iskemik ensefalopati sendromu, yenidoğan bebekte görülen emme güçlüğü, hipotoni, konvülziyon gibi nörolojik bulguların yanı sıra manyetik rezonans (MR) görüntülemede hipoksi alanlarının görülmesi ile tanınabilir. ${ }^{[11]}$ Yine de SP gelişme riskini kesin olarak yansıtan parametreler elde edilememiştir.

\section{Nöromotor Gelişim Basamaklarının Sorgulanması}

Nörolojik gelişim ince motor, kaba motor, dil ve kişisel sosyal olmak üzere dört temel alanda değerlendirilir. Sağlıklı bir bebek 1. ayında yüzüstü bırakıldığında başını hafifçe yukarı kaldırabilir, 3. ayında başını tutabilir, 4.-5. ayında destekli oturabilir, 6.-8. ayında desteksiz oturabilir, 8.-10. ayında emeklemeye başlar ve 12.-15. ayında yürür. Eğer bir bebek 2 . ayını doldurduğunda yüzüstü konulduğunda başını kaldıramıyorsa, dokuz ayını doldurduğunda desteksiz oturamıyorsa ve 18 ayını doldurduğunda yürüyemiyorsa o zaman kaba motor gelişim basamaklarının geriliğinden söz edilir. İnce motor gelişim basamaklarındaki önemli noktalar; 4. ayda cisimlere istemli uzanma, 6. ayda cisimleri bir elden diğer ele geçirebilme, 9. ayda başparmak ve işaret parmağı kullanarak küçük cisimleri kavrayabilmenin başlaması olarak özetlenebilir. Sağlıklı bir çocuk ilk iki yaşta her iki elini birden kullanır. İki yaşından önce el tercihinin olması hemiplejik SP için uyarıcı olmalıdır. Dil gelişiminde temel basamaklar; 2. ayda agulama, 3. ayda sesli gülme, 6.-8. ayda seslerin taklidi, 8.-10. ayda tek hecelerin başlaması, 12.-15. ayda anlamlı kelimelerin başlamasıdır. On sekizinci ayını dolduran bir çocuğun hiç anlamlı kelimesi yoksa ya da iki yaşında iki kelimelik, üç yaşında üç kelimelik basit cümleleri yoksa dil gelişim geriliğinden söz edilir. Kişisel sosyal gelişimde 3 . ayda gülümseme, 6.-8. ayda yabancıları ayırt edebilme, 12. ayda ismini bilme, 24. ayda başka çocuklar ile oyun oynamaya başlama temel basamaklar olarak sayılabilir. ${ }^{[12]}$ Tablo 1'de sağlıklı çocuğun gelişim basamakları özetlenmiştir. 
Tablo 1. Sağlıklı çocuğun gelişim basamakları ${ }^{[12]}$

\begin{tabular}{cllll}
\hline Yaş (ay) & Kaba motor & Ince motor & Dil & Kişisel sosyal \\
\hline 3 ay & $\begin{array}{l}\text { Traksiyon manevrasında başını } \\
\text { tutabilir }\end{array}$ & Elini spontan açar & Gülümser & Güler, sesler çıkarabilir \\
6 ay & Oturabilir & $\begin{array}{l}\text { Cisimleri bir elinden diğer eline } \\
\text { geçirebilir }\end{array}$ & $\begin{array}{l}\text { Sevip sevmediği şeyleri } \\
\text { belli eder }\end{array}$ & Babıldar \\
9 ay & Tutunarak kalkabilir & $\begin{array}{l}\text { Başparmak ve işaret parmağını } \\
\text { kullanarak cisimleri kavrayabilir }\end{array}$ & Küçük oyunlar oynayabilir & Sesleri taklit edebilir \\
12 ay & $\begin{array}{l}\text { Bir elinden tutulduğunda } \\
\text { yürüyebilir }\end{array}$ & $\begin{array}{l}\text { Komut verildiğinde cisimleri } \\
\text { bırakabilir }\end{array}$ & İsmini bilir & $\begin{array}{l}1-2 \text { anlamlı kelime } \\
\text { söyleyebilir }\end{array}$ \\
24 ay & Yardımla merdiven çıkabilir & Kaşık kullanabilir & Başkalarını taklit eder & $\begin{array}{l}\text { En az altı anlamlı kelime } \\
\text { söyleyebilir }\end{array}$ \\
& & Altı küp ile kule yapabilir & $\begin{array}{l}\text { Başka çocuklar ile oyun } \\
\text { oynar }\end{array}$ & $\begin{array}{l}2-3 \text { kelimelik cümleler } \\
\text { söyleyebilir }\end{array}$
\end{tabular}

Tablo 2. Primitif (ilkel) reflekslerin başlama, gelişim ve kayboluş zamanları ${ }^{[12]}$

\begin{tabular}{llll}
\hline Primitif refleks adı & Başlama zamanı & Tam geliştiği zaman & Süre \\
\hline Palmar yakalama refleksi & 28. gestasyonel hafta & 32. gestasyonel hafta & Postnatal 2.-3. ay \\
Arama refleksi & 32. gestasyonel hafta & 36. gestasyonel hafta & Postnatal 1. aydan sonra daha az belirgin \\
Moro refleksi & 28.-32. gestasyonel hafta & 37. gestasyonel hafta & Postnatal 3.-6. ay \\
Tonik boyun refleksi & 35. gestasyonel hafta & Postnatal 1. ay & Postnatal 6.-7. ay \\
Paraşüt refleksi & Postnatal 7.-8. ay & Postnatal 10.-11. ay & Hayat boyu
\end{tabular}

\section{Nörolojik Değerlendirme}

\section{Genel hareketlerin değerlendirilmesi}

Fetüs ve infant nörolojik sistemi, spesifik bir uyaran olmaksızın, endojen olarak çeşitli motor hareketlerin oluşmasını sağlar. Fetal dönemde 9.-12. haftalarda startle (ürkme), izole ekstremite hareketleri, seğirme, gerilme, esneme ve solunum hareketleri başlar. Fetal dönemden infantil döneme kadar gelişim esnasında çok çeşitli hareket paternleri görülür. Bunlar içinde, nörolojik sistemin fonksiyonel değerlendirilmesinde en etkili olan genel hareketlerin gözlemidir. Genel hareketler kompleks, sık ve düzgün bir gözleme izin verecek şekilde uzun sürelidir. Bu hareketler değişken şekillerde kol, bacak, boyun ve gövdede olmak üzere tüm vücutta gözlenir. Ekstremitelerin ekseni boyunca dönüş hareketleri ve hareket yönündeki hafif değişiklikler, onları akıcı hale getirerek, kompleks ve değişken ifadeyi yaratır. ${ }^{[13]}$ Uyanık bir infantta 3.-5. aylar arasında baskın olan, her yöne olabilen değişken hareketler fidgety (kıpır kıpır) hareketler olarak adlandırılır. Sinir sistemi bir hasar görürse genel hareketler, kompleks ve değişken karakterini kaybeder ve monotonlaşır. SP gelişimini \%97 duyarlılık ve \%89 özgüllükle öngörmeyi sağlayan iki önemli hareket paterni; hareketlerin düzgün ve akıcı karakterini kaybederek rijit bir hal alması ve genel hareketlerin fidgety (kıpır kıpır) karakterini yitirmesidir. ${ }^{[14,15]}$

\section{ilkel refleksler}

ilkel refleksler beyin sapından kaynaklanan, doğumda var olan, 6-9 ayda kaybolan motor reflekslerdir. Bunlar belirli dönemlerde belirir ve kaybolur. Beynin olgunlaşmasıyla ilkel reflekslerin baskınlığı azalır ve motor hareket becerilerini oluşturacak postüral yanıtlar belirginleşir. Bu reflekslerin alınması gereken zamanda alınmaması ya da kaybolması gereken zamanda kaybolmaması, bebeğin nörolojik gelişiminde bir sorun olduğunu düşündürür. Tablo 2'de ilkel reflekslerin belirme, gelişme ve kaybolma süreleri özetlenmiştir. ${ }^{[12]}$

\section{Nörolojik muayene bulguları}

Fizik muayenede aşırı tiz sesli ağlama, letarji, emme ve yutma güçlükleri, dil ile gıdaları dışarı itme, kas tonusunda artma ya da azalma, canlı/artmış derin 
tendon refleksleri, klonus varlığı ve taban cildi refleksinin ekstansör yanıtı (Babinski refleksinin pozitifliği) görülebilir. Taban cildi refleksine ekstansör yanıtın 0-2 yaşta fizyolojik olarak görülebileceği, ancak asimetrik olmasının her yaş için patolojik olduğu unutulmamalıdır. Erken dönemde saptanan kas tonusunda azalma yani hipotoni 2-3 yıl içinde yerini spastiste ya da distoniye bırakabilir. İlk üç ayda bebeklerde fizyolojik hipertoni (kas tonusunda artış) görülebilir. Üçüncü aydan sonra başparmak avuç içinde ve parmaklar yumruk şeklinde (kortikal yumruk/kortikal fisting) ise fizyolojik olmayan hipertoniden söz edilir. Hipertoni iki şekilde görülebilir. Tonus artımı yalnızca agonist ya da antagonist kaslarda görülürse sustalı çakı fenomeninden yani spastisiteden söz edilir. Spastisitede, genellikle etkilenen tarafta kol, bacaktan daha fazla tutulmuştur ve üst ekstremitede fleksör kaslar, alt ekstremitede ise ekstansör kaslar daha fazla etkilenir. Hem agonist hem de antagonist kaslarda tonus artımı varsa o zaman dişli çark ya da kurşun boru fenomeninden, yani rijiditeden söz edilir. Bebek yüzüstü yatırıldığında kalçanın gövdeden yüksekte olması, yenidoğanda bacaklarda aşırı ekstansiyon olması, asimetrik duruş distoni ya da spasitisite için anlamlı olabilir. Koltuk altlarından tutulup kaldırıldığında bacaklarda çaprazlama olması ve opistotonus postürü hipertoniyi düşündüren diğer bulgulardır. Hemiplejik SP'li bir infantın etkilenen ekstremitesinde spontan hareketlerin azalmış olduğu göze çarpar. Bu olgularda yürüme 18-24. aya kadar gecikebilir ve yürürken genellikle oraklama görülür. Eğer her iki alt ekstremite birden etkilenmiş ise, o zaman yürüme daha da zorlaşır ve her iki bacakta çaprazlama/makaslama göze çarpar. ${ }^{[16]}$

Diskinetik tip SP, tüm SP olgularının \%15-20'sini oluşturur. Aksiyel hipotoni ve ekstremitelerde rijidite tipi tonus artımı görülür. Bu olgularda orofarengeal kaslar da çoğunlukla etkilendiğinden yutma ve konuşma güçlükleri görülür. Etiyoloji genellikle tama yakın hipoksi ya da bilirubin ensefalopatisidir. ${ }^{[17]}$

\section{Hammersmith infant nörolojik değerlendirme skalası}

Hammersmith infant nörolojik değerlendirme (HINE) skalası, 2-24 ay arası infantlara uygulanabilen, klinik nörolojik muayenenin skorlanarak yapıldığı bir skaladır. Kranial sinir fonksiyonlarının, postürün, hareketin niteliksel ve niceliksel özelliklerinin, kas tonusu, refleksler ve reaksiyonların skorlandığı 26 maddeden oluşur. Her madde 0, 1, 2, 3 olarak puanlanır ve toplam skor 0 ile 78 arasında değişir. HINE skalasının ardışık kullanımı SP ve diğer nöromotor bozuklukların erken bulgularını saptamada önemli olduğu kadar, uzun dönem motor sonuçlar hakkında da bilgi verir. ${ }^{[18]}$ Haataja ve ark. bir çalışmada, düzeltilmiş 6-15 ay arası preterm infantlarda, skorun 64'ün üzerinde olmasının \%98 duyarlılık ve \%85 özgüllük ile bağımsız yürüyebilme, skorun 52'nin altında olmasının ise SP ve ciddi motor bozukluklar için prediktif olduğu sonucuna varmıştır. ${ }^{[19]}$

\section{Merkezi Sinir Sisteminin Görüntülemesi}

SP'li çocukların \%70-90'ında kranial görüntülemelerde patoloji saptanmaktadır. ${ }^{[20]}$ Yenidoğanlarda doğum öncesi, doğum ve perinatal döneme ait risk faktörleri varsa, 32. gestasyonel haftadan daha erken doğum öyküsü varsa ve muayenede nörolojik patoloji saptanırsa görüntüleme yapılmalıdır. ${ }^{[21]}$ Görüntüleme çalışmaları, asfiktik yenidoğanlarda doku hasarlanması, intrakranial kanamaların varlığı ve derecesi, santral sinir sistemi (SSS) gelişimsel anomalilerinin varlığı hakkında bilgi verir.

Transfontanel ultrasonografi (US), riskli bebeklerde tercih edilen non-invaziv, sedasyon gerektirmeyen ve yatak başında da uygulanabilen bir görüntüleme yöntemidir. US ile ventriküler sistem, korpus kallosum, bazal ganglionlar ve koroid pleksus değerlendirilir. Intraventriküler hemoraji (iVH), subependimal, intraserebral kanamaların ve ventrikül boyutlarının takibinde ilk hafta ve aylarda, kolay uygulanabilir olması nedeniyle, değerlidir. Bin beş yüz gramın altında doğan bebeklere yaşamın 4.-7. günleri arasında rutin olarak yapılması önerilir. Ventrikül boyutları stabil oluncaya dek haftada bir kez ve 3. ayda US tekrarı önerilir. Lateral ventriküllerin ön, arka boynuzları, korona radiatada PVL ve kistik alanların varlığı yaşamın 2. haftasından sonra gösterilebilir. Transfontanel US bulgularına göre intrakranial kanama dört evrede sınıflandırılır. Kanama yalnızca subependimal germinal matrikse sınırı ise evre 1 , ventrikül içine sınırı ise evre 2 , ventrikül içi kanamaya ventrikülde genişleme eşlik ediyorsa evre 3 , parankim içi kanama varsa evre 4 olarak sınıflandırılır. ${ }^{[22]}$ Ancak ön fontanelden yapılan transfontanel US'nin beyin sapı ve posterior fossanın görüntülenmesinde duyarlı olmadığı unutulmamalıdır. Preterm ve düşük doğum ağırlıklı bebeklerde yapılmış çalışmalar, transfontanel US'de kistik PVL, evre 3 ve 4 intraventriküler kanama ve persistan ventriküler dilatasyon varlığının kötü nörolojik sonuçlarla ilişkili olduğunu ortaya koymuştur. ${ }^{[23]}$

Bilgisayarlı beyin tomografisi (BBT), US'ye göre beyin anatomisini, bazı konjenital malformasyonları, intrakranial kanama bulgularını ve porensefalik kistleri tanımada daha yararlıdır. Hipoksik iskemik hasara bağlı parankimde hipodens alanlar ve zor doğuma bağlı kanama alanları görülebilir. BBT bulgularının ağırlığı ile uzun dönem nörolojik sonuçlar arasında güçlü bir ilişki olduğunu gösteren çalışmalar mevcuttur. ${ }^{[24]}$ Ancak parankim patolojilerini göstermede BBT'nin MR görüntülemeye göre daha az duyarlı olması ve BBT'de 
radyasyon maruziyetinin olması nedeniyle, BBT fazla tercih edilmemektedir.

Kranial MR, SSS'nin anatomik görüntülemesi ile ilgili daha ayrıntılı bilgi verir. Klinik olarak stabil yenidoğanlarda asfiksiye bağlı hasarlanmayı değerlendirmede kranial MR tercih edilmelidir. Diffüzyon MR ise, hipoksinin görüntüleme bulgularını daha erken dönemde yakalayabilir ve prognozu göstermede konvansiyonel kranial MR'den daha değerlidir. Literatürde hipoksi öyküsü olan yenidoğan bebeklerin diffüzyon MR'sinde diffüzyon kısıtlılığının olmamasının iyi nörolojik sonuçlarla ilişkili olduğunu belirten yayınlar mevcuttur. ${ }^{[25]}$ Konvansiyonel MR, beyin parankimini göstermede ve miyelinizasyonun izleminde daha duyarlı bir tetkiktir. Asfiksiden sonraki ilk 10 gün içinde çekilen kranial MR'lerde üç farklı patolojik görünüm dikkat çeker. Zamanında doğanlarda en çok derin asfiksiye bağlı talamus ve bazal ganglion lezyonları görülür. İkinci sıklıkta serebral korteks ve subkortikal beyaz cevher patolojileri görülür. PVL genellikle prematürelerde veya 34.-35. gestasyon haftasından önce inutero asfiksiye maruz kalan yenidoğanlarda sık görülür. Term infantların \%26'sında da MR'de PVL gösterilmiştir. Beyin sapı ve serebellum patolojileri daha az sıklıkta görülür. Bazal ganglion ve talamusta kontrast madde birikimi doku nekrozunu gösterir ve kötü prognoz göstergesidir. Tek veya iki taraflı olabilen pariyetal ve pariyeto-oksipital bölgedeki fokal parankimal kanamalar, genellikle atrofi, hipomiyelinizasyon ve hemosiderin birikimi ile sonuçlanır. Bazal ganglion hemorajileri asfiktik infantların \%5'inde, iVH'si olan term infantların \%63'ünde görülür. Kontrol MR'lerde bazal ganglion hemorajileri kist veya kalsifikasyon olarak görülür. Perinatal asfiksiye bağlı miyelinizasyon gecikmesinin gösterilmesi en iyi yaşamın 7.-8. ayından sonra mümkündür. Prematürelerde PVL'ye miyelinizasyonda gecikme eşlik edebilir. Diskinetik tip SP'lilerde, MR'de bazal ganglion lezyonları dikkat çeker. Hemiparezik SP'li hastalarda, kanama ya da bir arter sulama alanına uyan infarkta ikincil porensefalik kist oluşumu dikkat çeker. Neonatal dönemde çekilen MR'de PVL, kistik PVL, hemorajik infarkt, progresif ventrikülomegali, bazal ganglion hasarı ve serebellumda kanama bulgularının olması izlemde SP gelişimi için prediktiftir. Yalnız neonatal dönemde çekilen beyin MR'de henüz miyelinize olmamış alanlardan dolayı bazı beyaz cevher lezyonlarının gözden kaçabileceği unutulmamalıdır. Bu nedenle klinik bulguları SP ile uyumlu olan ancak görüntüleme bulguları uyumlu olmayan olguların beyin MR'sinin 2-2,5 yaş civarı tekrar çekilmesi önerilmektedir. ${ }^{[26]}$ Beyin MR, SP ön tanısının doğrulanmasının yanı sıra, SP ile karışabilecek bazı metabolik ve genetik patolojilerin aydınlatılmasına da katkıda bulunur.
Klinik pratikte çok sık kullanılmasa da proton MR spektroskopi (MR-S) ve pozitron emisyon tomografi (PET) de hipoksik iskemik hasar hakkında bilgi verebilir. Perinatal asfiksinin ilk saatlerinde MR-S'te inorganik fosfat konsantrasyonunda artış, fosfokreatinde azalma görülür. Laktat/kreatin ve laktat/ $\mathrm{N}$ asetil aspartat oranlarına bakılarak laktatın arttığı görülür. MR-S doğumdan 1-2 hafta sonra yapıldığında $\mathrm{N}$-asetil aspartat/kreatin oranının azaldığı, laktat seviyelerinin ise normal olduğu görülür. PET'te asfiksinin ilk saatlerinde serebral kan akımında azalma, yaşamın ilk ve ikinci haftalarında ise kan akımında artma görülür. Ayrıca PET ile total ve bölgesel serebral glukoz metabolizması değerlendirilebilir. Normal infantlarda derin kortikal madde, talamus, bazal ganglionlar, duysal ve motor korteks metabolik olarak aktif alanlardır. PET, doğumdan sonraki 4. ve 24. günler arasında yapılırsa, asfiksiye bağlı hasarlanmanın derecesiyle ters orantılı serebral glikoz metabolizmasında azalma görülür. ${ }^{[27]}$

\section{SEREBRAL PALSIDE MEDIKAL TEDAVi}

Spastik SP'li olgularda spastisiteyi, diskinetik SP'li olgularda distoniyi gidermek ya da azaltmak bazı medikal tedavilerle mümkündür. Baklofen $\mathrm{GABA}_{\mathrm{B}}$ (gama-aminobütrik asit), benzodiazepin grubu ilaçlar ise $G_{A B A}$ üzerinden etki göstererek spastisitenin azaltılmasını sağlar. Alfa ${ }_{2}$-adrenerjik reseptör agonisti olan tzanidinin SP'li çocuk ve adolesanlarda spastisitenin farmakolojik tedavisinde kullanılabileceği Amerikan Pediatri Akademisi tarafindan belirtilmiştir (Düzey C). Sarkoplazmik retikulumdan kalsiyum salımını inhibe ederek direkt çizgili kas üzerine anti-spastik özellik gösteren dantrolen de spastisitenin medikal tedavisinde kullanılabilir; ancak ülkemizde bulunmamaktadır. ${ }^{[28]}$ Distonik tip SP'li olguların yakınmalarının azaltılmasında antikolinerjik ilaçlar kullanılabilir. Bu grupta trihekzifenidil, biperiden, atropin, porsiklin, orfenadrin, skopalamin ve benztropin gibi ilaçlar mevcuttur. Biperiden ve atropin dışındaki ilaçlar ülkemizde mevcut değildir. Jeneralize distoni varlığında bir periferik dekarboksilaz inhibitörü ile birlikte levodopa verilebilir. Veziküler monoamin taşıyıcılarını inhibe ederek dopaminin veziküler depolarını boşaltan bir ilaç olan tetrabenazin ise hiperkinetik hareket bozukluklarının ve distonin farmakolojik tedavisinde kullanılabilir. ${ }^{[29]}$

Çocuklarda engelliliğin en sık nedeni olan SP'nin tanısı öykü, nörolojik muayene ve görüntüleme bulgularının değerlendirilmesi ile mümkündür. Ancak motor fonksiyon bozukluğu daha geç dönemde fark edildiği için çoğunlukla erken süt çocukluğu döneminde tanı koymak güç olabilir. Nöronal plastisitenin en aktif olduğu dönemde tedavi başlanması iyi nörolojik sonuçlarla ilişkili olduğu için, erken tanı büyük önem taşır. 
Öyküdeki risk faktörlerinin iyi belirlenmesi ve riskli bebeklerin yakın izlemi erken tanıdaki en önemli noktalardandır. Aşırı tiz sesli ağlama, letarji, emme ve yutma güçlükleri, konvulziyon, dil ile gıdaları dışarı itme, ilkel reflekslerin beklenen seyri göstermemesi, gelişim basamaklarına geç ulaşma ya da ulaşamama, genel hareketlerin akıcı özelliğini kaybedip rijit bir hal alması ve fidgety (kıpır kıpır) özelliğini yitirmesi, anormal tonus ve postür ile düşük HINE skorları SP'nin ilk altı ayda görülebilen; ilkel reflekslerin normal seyir göstermemesi ve 6. aydan sonra da devam etmesi, düşük HINE skorları, gelişim basamaklarına geç ulaşma, anormal tonus ve postür SP'nin ilk altı aydan sonra görülebilen bulgulardır.

\section{KAYNAKLAR}

1. Graham HK, Rosenbaum $P$, Paneth $N$, Dan B, Lin JP, Damiano DL, Becher JG, Gaebler-Spira D, Colver A, Reddihough DS, Crompton KE, Lieber RL. Cerebral palsy. Nat Rev Dis Primers 2016;2:15082. https://doi.org/10.1038/nrdp.2015.82

2. Little WJ. Course of lectures on the deformities of the human frame. Lancet 1844;41(1072):P809-15. https://doi. org/10.1016/S0140-6736(02)64521-0

3. Rosenbaum $P$, Paneth $N$, Leviton $A$, Goldstein $M$, Bax $M$, Damiano D, Dan B, Jacobsson B. A report: the definition and classification of cerebral palsy. Dev Med Child Neurol Suppl 2007;109:8-14. https://pubmed.ncbi.nlm.nih.gov/17370477/

4. ACPR Group. Australian Cerebral Palsy Register Report 2016 (Birth Years 1993-2009). https://cpregister.com/wpcontent/uploads/2018/05/ACPR-Report_Web_2016.pdf

5. Herskind A, Greisen G, Nielsen JB. Early identification and intervention in cerebral palsy. Dev Med Child Neurol 2015;57(1):29-36. Crossref

6. Baird G, McConachie H, Scrutton D. Parents' perceptions of disclosure of the diagnosis of cerebral palsy. Arch Dis Child 2000;83(6):475-80. Crossref

7. Hirvonen M, Ojala R, Korhonen P, Haataja P, Eriksson K, Gissler M, Luukkaala T, Tammela O. Cerebral palsy among children born moderately and late preterm. Pediatrics 2014;134(6):e1584-93. Crossref

8. Jacobsson B, Hagberg G. Antenatal risk factors for cerebral palsy. Best Pract Res Clin Obstet Gynaecol 2004;18(3):42536. Crossref

9. MacLennan AH, Thompson SC, Gecz J. Cerebral palsy: causes, pathways, and the role of genetic variants. Am J Obstet Gynecol 2015;213(6):779-88. Crossref

10. Platt MJ, Pateliadis CP HM. Aetiological factors. In: Pateliadis $\mathrm{CP}$, editor. Cerebral palsy: a multidisciplinary approach, 3 rd ed. Cham, Switzerland: Springer International Publishing; 2018. p.49-58.

11. Bano S, Chaudhary V, Garga UC. Neonatal hypoxic-ischemic encephalopathy: a radiological review. J Pediatr Neurosci 2017;12(1):1-6. Crossref

12. Onigbanjo MT, Fiegelman S. The first year. In: Kliegman RM, Geme JS. Nelson Pediatrics, 21th ed. 2019. p.1122-36.

13. Prechtl HFR. Qualitative changes of spon taneous movements in fetus and preterm in fant are a marker of neurological dysfunction. Early Hum Dev 1990;23(3):151-8. Crossref
14. Einspieler C, Prechyl HFR. Prechtl's assessment of general movements: a diagnostic tool for the functional assessment of the young nervous system. Ment Retard Dev Disabil Res Rev 2005;11(1):61-7. Crossref

15. Kwong AKL, Fitzgerald TL, Doyle LW, Cheong JLY, Spittle AJ. Predictive validity of spontaneous early infant movement for later cerebral palsy: a systematic review. Dev Med Child Neurol 2018;60(5):480-9. Crossref

16. Swaiman KF. Neurologic examination after the newborn period until 2 years of age. In: Swaiman KF, Ashwal S, Ferriero DM, Nina F Schor. Pediatric Neurology: Principles and Practice, 5th ed. US: Saunders; 2012. p.33-42.

17. Himmelmann K, McManus V, Hagberg G, Uvebrant P, Krageloh-Mann I, Cans C; SCPE collaboration. Dyskinetic cerebral palsy in Europe: trends in prevalence and severity. Arch Dis Child 2009;94(12):921-6. Crossref

18. Dubowitz L, Ricciw D, Mercuri E. The Dubowitz neurological examination of the full-term newborn. Ment Retard Dev Disabil Res Rev 2005;11(1):52-60. Crossref

19. Haataja L, Mercuri E, Regev R, Cowan F, Rutherford M, Dubowitz V, Dubowitz L. Optimality score for the neurologic examination of the infant at 12 and 18 months of age. J Pediatr 1999;135(2):153-61. Crossref

20. Hoon $\mathrm{AH}$ Jr. Neuroimaging in cerebral palsy: Patterns of brain dysgenesis and injury. J Child Neurol 2005;20(12):9369. Crossref

21. Russman BS, Ashwall S. Evaluation of the child with cerebral palsy. Semin Pediatr Neurol 2004;11(1):47-57. Crossref

22. Leviton A, Kuban K, Paneth N. Intraventricular haemorrhage grading scheme: time to abandon? Acta Paediatr 2007;96(9):1254-6. Crossref

23. Vohr BR, Wright LL, Poole WK, McDonald SA. Neurodevelopmental outcomes of extremely low birth weight infants <32 weeks' gestation between 1993 and 1998 . Pediatrics 2005;116:635-43. Crossref

24. Robertson CM, Finer NN, Grace MG. School performance of survivors of neonatal encephalopathy associated with birth asphyxia at term. J Pediatr 1989;114(5):753-60. Crossref

25. Cowan FM, Pennock JM, Hanrahan JD, Manji KP, Edwards A. Early detection of cerebral infarction and hypoxic ischemic encephalopathy in neonates using diffusionweighted magnetic resonance imaging. Neuropediatrics 1994;25(4):172-5. Crossref

26. Spittle AJ, Morgan C, Olsen JE, Novak I, Cheong JLY. Early diagnosis and treatment of cerebral palsy in children with a history of preterm birth. Clin Perinatol 2018;45(3):409-20. Crossref

27. Menkes JH, Sarnat HP. Perinatal Asphyxia and Trauma. In: Menkes JH, Sarnat HB, Maria BL. Child Neurology, 7th ed. Philadelphia: Lippincott Williams and Wilkins; 2006. p.367-431.

28. Chung CY, Chen CL, Wong AMK. Pharmocotherapy of spasticity in children with cerebral palsy. J Formos Med Assoc 2011;110(4):215-22. Crossref

29. Robertie A, Leydet J, Demonceau N, Echenne B. Pharmalogical treatment of childhood dystonia. In: Nardocci N, FernandezAlvarez E, editors. Movement disorders in children: a clinical update with video recordings. UK: John Libbey Eurotext Ltd; 2007. p.59-66. 